\title{
Learning internal iliac artery ligation and pelvic ureter course through cadaveric dissections
}

\author{
Arun R. Mahale ${ }^{1 *}$, Anjali G. Gosavi², Mahesh S. Ugale ${ }^{3}$, Chaya V. Diwan ${ }^{4}$, Shivaji B. Sukre
}

\begin{abstract}
${ }^{1}$ Department of Obstetrics and Gynecology, MIMSR Medical College, Latur, Maharashtra, India ${ }^{2}$ Department of Anatomy, Ashwini Rural Medical College and Hospital, Solapur, Maharashtra, India ${ }^{3}$ Department of Anatomy, MIMSR Medical Collge, Latur, Maharashtra, India ${ }^{4}$ Department of Anatomy, SC Govt Medical College, Nanded, Maharashtra, India ${ }^{5}$ Department of Anatomy, Govt Medical College, Aurangabad, Maharashtra, India
\end{abstract}

Received: 26 June 2018

Accepted: 08 September 2018

\section{*Correspondence:}

Dr. Arun R. Mahale

E-mail: mahales@hotmail.com

Copyright: (c) the author(s), publisher and licensee Medip Academy. This is an open-access article distributed under the terms of the Creative Commons Attribution Non-Commercial License, which permits unrestricted non-commercial use, distribution, and reproduction in any medium, provided the original work is properly cited.

\section{ABSTRACT}

Background: Few surgical procedures, although vital, are not learnt and mastered during postgraduate courses in Obstetrics and Gynecology. Internal iliac artery ligation and tracing course of ureter are few of such surgical procedures. Cadaveric dissection sessions organized during postgraduate courses and as CME sessions (continued medical education) have proved useful in learning such unlearnt procedures. This article shares experiences from teaching internal iliac artery ligation, pelvic ureter course tracing and principles of many other unusual gynaecological surgical procedures to Obstetrics and Gynecology specialists and postgraduate students through CME programs involving cadaveric dissection.

Methods: This involved organizing and conducting four cadaveric dissection CME workshops at three different teaching institutions. The components of these CMEs were lectures with power point presentations and two-way audio-visual interactive sessions while pelvic anatomy was demonstrated on cadavers through live dissections. Each CME was concluded by tactile experience to each delegate by handling the dissected cadavers; this was made possible by limiting delegate registration to 50 at each CME.

Results: The surgical skills of internal iliac artery ligation and tracing course of pelvic ureter, which are not adequately and confidently learnt in routine postgraduate tenure, could be effectively transferred through cadaveric dissection.

Conclusions: Revisiting anatomy dissection halls helps in learning rare but lifesaving surgical techniques. This can be achieved by arranging cadaveric dissection CMEs for practicing specialists. Such CMEs should be organized regularly and should be integrated into postgraduate curriculum.

Keywords: Cadaveric dissection, Internal iliac artery ligation, Surgical anatomy Ureter course

\section{INTRODUCTION}

In developing countries, obstetric haemorrhage is still the leading cause of maternal death and severe maternal morbidity. Along with many other modalities, internal iliac artery ligation is a proven method of controlling obstetric haemorrhage and also has an established place in limiting blood loss in certain gynecological surgical conditions. $^{1,2}$ Internal iliac artery ligation has the advantage of requiring less operating time and fertility preserving ability when compared to obstetric hysterectomy. ${ }^{3}$ Bilateral internal iliac artery ligation works by reducing blood flow and lowering pulse pressure beyond the site of ligation, thus converting the 
arterial blood flow to that of a venous blood flow. This takes away the trip hammer effect of high arterial pulse pressure on dislodging the clot, which encourages clot formation and its retention at the injury site. ${ }^{4}$ Common surgical procedures are thoroughly learned by assisting the specialists and consultants during postgraduate training, however less frequent procedures easily escape the training. These unusual procedures require thorough knowledge of pelvic anatomy and therefore learning anatomy is crucial to safely and confidently carrying out such essential though uncommon surgical procedures. This can be achieved from revisiting anatomy dissection halls and attending cadaveric dissection CME (continued medical education) workshops, which can enable the obstetricians and gynaecologists in focused learning and adding confidence to their surgical skills. ${ }^{5,6}$ Amongst the various methods that are currently used for surgical training, simulating surgery in human cadavers is the closest to actual practice. It still remains the most effective means to impart anatomical knowledge during the undergraduate and postgraduate medical training period. $^{7}$ The need of such training and evidence from experience of such dissection sessions is also stressed in the literature. ${ }^{8-10}$ Cadaver dissection learning has been established in ENT, orthopaedic and plastic surgery training but is still in a nascent stage in Gynecology. Herewith we share our experience of four cadaveric workshops designed to add and improve the surgical skills of general obstetricians and gynaecologists. The article also advices on how to organize a cadaveric dissection session for learning Gynecology surgery related pelvic anatomy.

\section{METHODS}

In this regard we took postgraduate students of gynecology to anatomy department dissection hall during the period when 'abdomen and pelvis dissection sessions' of first year MBBS students were in progress. However, for practicing gynecologists and for obstetrics and gynecology teachers from other medical colleges we organized special CME programs. We have an accumulated experience of four such cadaveric dissection workshops conducted at three medical colleges over a period of seven years. All these training sessions were registered with state medical council for accreditation points. The workshops were titled as "Understanding Gynec Surgery from Cadaveric Dissection" and "Surgical Anatomy for Safe Surgery". These workshops are coefforts of gynecologists and anatomists; and is a team work involving dissection hall technicians, curators, and audio-visual system technicians. All workshops had limited delegate registration to permit personal direct tissue touch and handling (tactile) experience. Other than authors, workshop faculty were medical teachers from gynecology and anatomy departments. Formalin preserved cadavers were used in these CMEs.

Organizing cadaveric workshops: female cadavers were specially identified and reserved for this event. Fatty cadavers consume lot of time and delay the demonstration of main desired anatomy, hence thin cadavers were preferred. Similarly, young cadavers were preferred as the pelvic organs are well defined as against their atrophic nature in geriatric cadavers. The incisions and steps of dissection done in these events were not always along the principles of anatomy dissection inherited from manuals of dissection but were planned according to the therapeutic surgery carried out in operations theatres. This required a lot of discussion with anatomists.

\section{Infrastructure}

- Dissection hall

- Female cadavers

- Dissection instruments

- Special instruments: Mixter forceps, Babcock clamp are two essentials for demonstrating internal iliac artery ligation and course of ureter.

- Good illumination

- Two-way audio-visual system.

- A class room in close proximity, for audience interaction through audio-visual aids.

- Surgical linen, gowns, gloves, laser pointers, suction machine, mops are other necessities.

\section{Pre-event preparations}

As the cadavers are stored for a varied duration, the abdominal wall does not have stretching ability like live bodies have. The organs in cadavers are tightly pressed on each other and cannot be pushed away easily from one another. Similarly, because of the long-standing weight of the unmoving organs the investing areolar tissue surrounding the organs is compressed making dissection experience very different when compared with live bodies. Dissecting such bodies just at the final event makes demonstration of surgical anatomy difficult and incomplete.

For these reasons the bodies were dissected a day prior in such a way that anatomy of the abdominal wall could be demonstrated layer by layer in the final event without loss of time. This could revise steps and anatomy related to the opening of the abdomen during surgery. However, the main dissection of demonstration of locating internal iliac artery, its ligation, and tracing the course of ureter was done at the final event as a live procedure. The small intestine was removed from ilio-caecal junction till jejuno-ilial junction by dividing the mesentery.

This is necessary as packing the small intestine away from the dissection field is not possible because of stiff abdominal walls in the cadavers. This was done a day prior to the main event. The areolar tissue from posterior retroperitoneal spaces and broad ligament spaces are obliterated in cadavers. These spaces were infused with saline solution which allowed a good demonstration of anatomy at these sites. The workshop was rehearsed with 
the local faculty team in its completeness a day prior because of its unusual nature. Two cadavers are required to conduct one workshop; these cadavers subsequently are available for undergraduate learning without loss of anatomical details. Formaldehyde neutralization should be satisfactorily done. So far four such workshops are conducted. The main interest of delegates was learning internal iliac artery ligation. Unedited DVDs were made available to the delegates for their revision.

\section{Demonstrating internal iliac artery ligation and ureter}

The steps we followed in demonstrating the anatomy related to internal iliac artery ligation and course of ureter are as follows:

Step 1: Round ligament (RL), ovario-pelvic ligament (OPL) and anterior superior iliac spine (ASIS) are clearly identified as important landmarks.

Step 2: Peritoneum of broad ligament between these two ligaments is lifted.

Step 3: Incising this peritoneum and extending the incision towards anterior superior iliac spine.

Step 4: The so created two folds of peritoneum are labelled as infero-lateral and supero-medial.

Step 5: Bluntly separating the areolar tissue between these two folds exposes psoas muscle at the lateral end with genito-femoral nerve on it.

Step 6: Inside the psoas muscle is seen a big artery.

Step 7: This artery is traced superiorly by separating areolar tissue on it; this leads to a bifurcation from which a big artery is seen descending into the pelvis.

Step 8: Thus, common iliac artery (CIA), external iliac artery (EIA), and internal iliac artery (IIA) are identified and clearly labelled (Figure 1).

Step 9: Gentle separation of areolar tissue inside external iliac artery identifies external iliac vein (EIV) between internal iliac artery and external iliac artery. This vein is postero-medial to the external iliac artery.

Step 10: Marking a 4 to $5 \mathrm{~cm}$ mark down from the bifurcation along the internal iliac artery.

Step 11: The placement of Mixter (right angle tipped clamp) forceps is explained. It is impressed that instrument should be passed below the internal iliac artery from lateral to medial side.

This makes the shoulder (also called sole and heel) of the instrument to rest on the vein and the tip does not prick the vein wall. Passing the instrument from medial side of the internal iliac artery makes the instrument tip to prick the external iliac vein wall and injure it.

Step 12: Pulling a non-absorbable suture around the artery.

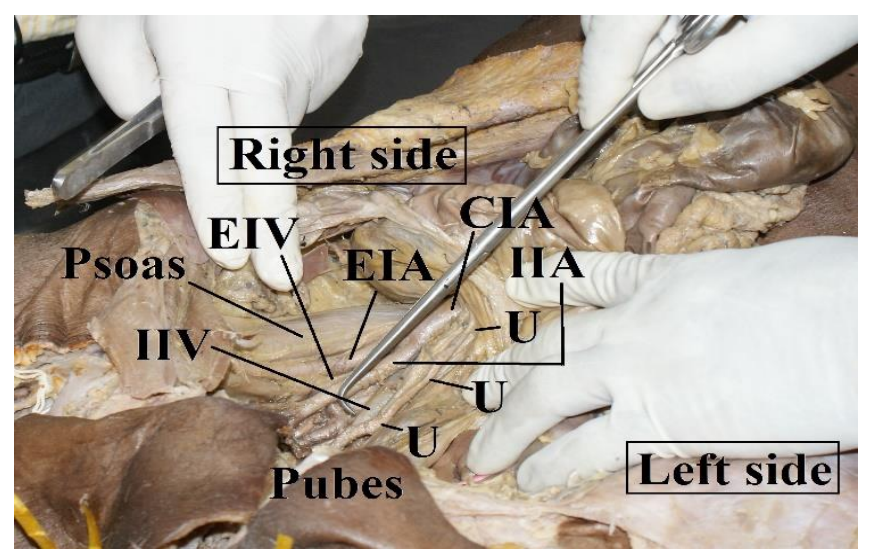

CIA: Common iliac artery, EIA: External iliac artery, IIA: Internal iliac artery, EIV: External iliac vein, IIV: Internal iliac vein, U: Ureter.

Figure 1: Photograph showing anatomical structures labelled.

In this method as the external iliac artery is identified first and it guides to the common and internal iliac artery, inadvertent ligation of external iliac is never a possibility. As the broad ligament is opened away from the pelvic brim (opened between round ligament and ovario-pelvic fold), locating ureter at the beginning is not necessary. Subsequently ureter is seen lying attached underneath the supero-medial fold and does not come into the area of internal iliac artery ligation.

\section{Demonstrating course of pelvic ureter}

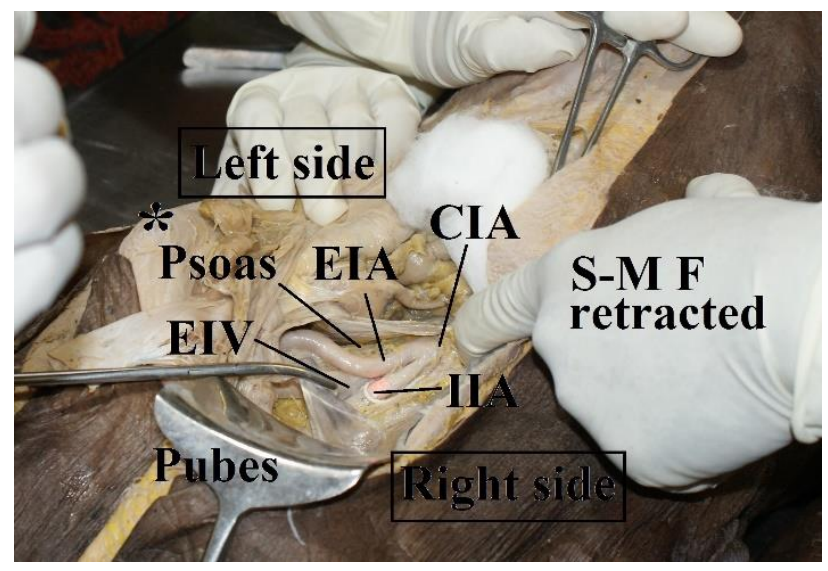

EIA: External iliac artery, CIA: Common Iliac Artery, IIA: Internal iliac artery, EIV: External Iliac Vein, SMF: Superomedial fold of peritoneum. *Anterior superior iliac spine.

Figure 2: Photograph showing anatomical landmarks to revise internal iliac artery ligation. 
Everting the edge of supero-medial fold of peritoneum exposes the ureter at the brim of pelvis (at the bifurcation of common iliac artery); it is then traced downwards lying supero-lateral to the utero-sacral ligaments and medial to the internal iliac artery (Figure 2).

The course of ureter (U) from its crossing over the bifurcation of common iliac artery (at pelvic brim) till its passage beneath the uterine artery was clearly demonstrated. Uncommonly used laparotomy incisions were also demonstrated, Figure 3 illustrates Cherney incision. This enabled the delegates to revise retropubic space anatomy. Other areas on which gynaecologic surgeons showed interest are interiliac trigon related to presacral neurectomy and the course of the tape in TOT (transobturator tape) and TVT (tension free vaginal tape) procedures.

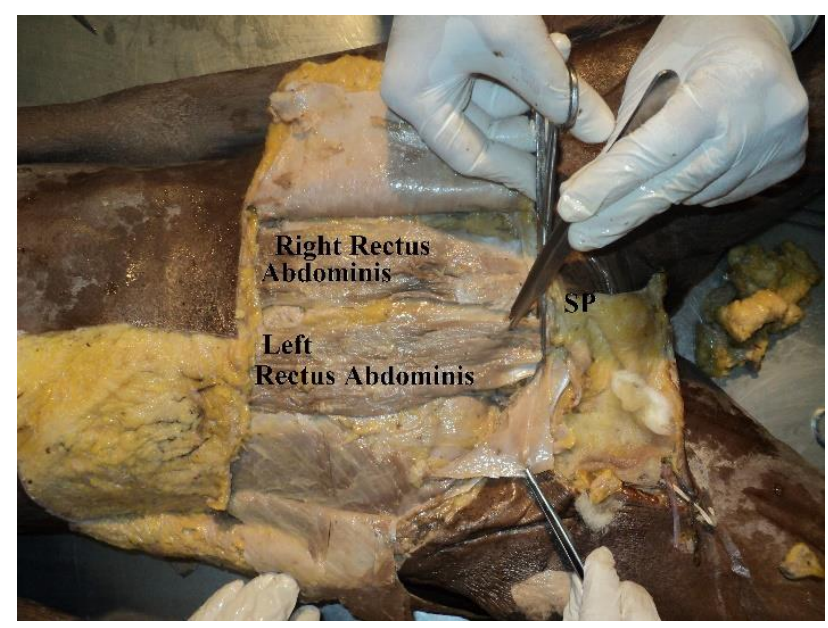

Figure 3: Photograph showing principle of Cherney incision.

\section{Other teaching aids}

An articulated pelvis, power point slides showing anatomy related to the topics covered in to the event proved very helpful in fulfilling the purpose of workshop.

\section{RESULTS}

First workshop was restricted to 50 delegates. Because of heavy rush and persistent demands the subsequent workshops the restriction to delegates registration number was extended to 100. All delegates participated in the last session of workshop which consisted of the personal direct tissue touch and handling (tactile) experience on the cadaver. The results were impressive. Many obstetricians started doing internal iliac artery ligation when needed; earlier they depended on general surgeons and onco-surgeons, these specialists often were not promptly available. Onco-surgeons and intervention radiologists are available only in big cities. There were requests for more such workshops. Third and fourth workshops were organized at different places because of the demand from those areas. Now in our region most of the towns have obstetricians who can safely perform internal iliac ligation. All delegates learned to trace the ureter from pelvic brim till its entry into the ureteric tunnel. Other areas of interest were vessels of the anterior abdominal wall (Figure 4, 5), the inter-iliac artery trigon, and retro-pubic area.

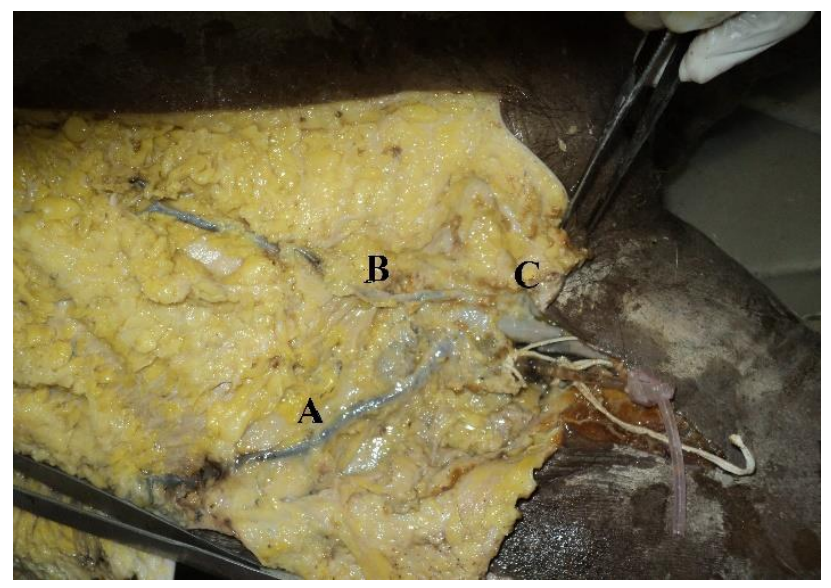

Figure 4: Photograph showing superficial vessels of anterior abdominal wall. A: Superficial circumflex iliac vessels, B: Superficial epigastric vessels, C: External pudendal vessels.

Figure 1 and 5 illustrate the pelvic structures on which the delegates did revision by directly handling and touching the structures, which was the last session of workshop. All delegates being non-oncosurgeons appreciated this learning as a fascinating learning experience.

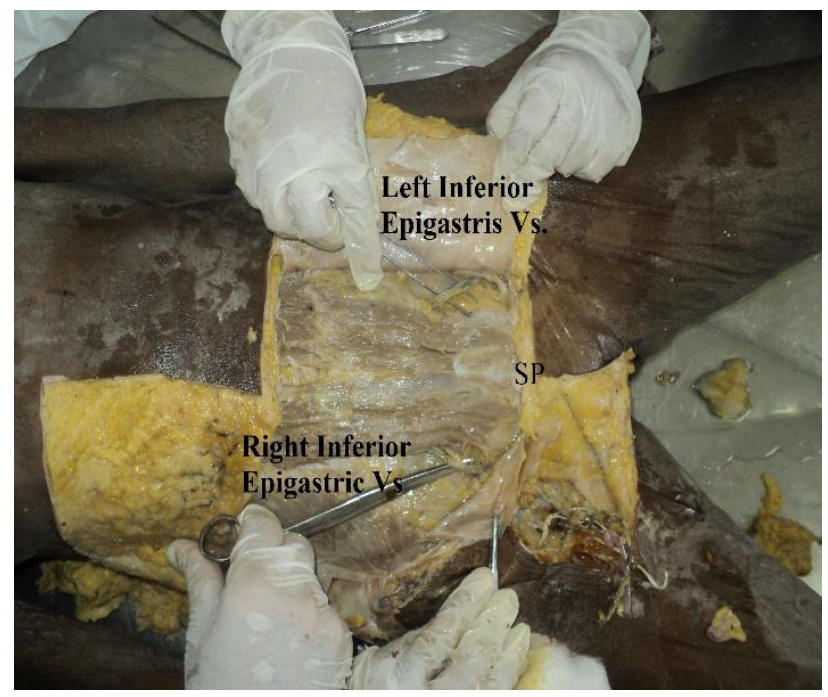

Figure 5: Photograph showing inferior epigastric vessels.

\section{DISCUSSION}

Knowing the procedure of internal iliac artery ligation, its pathophysiology is an important and lifesaving part controlling obstetric and gynecologic hemorrhages. ${ }^{1-4}$ 
The postgraduate education and training in surgical subjects does not contain cadaveric dissection as an essential and compulsory component of the curriculum. Postgraduate students during their tenure as trainee are exposed mainly to common surgical procedures, which form the major component of services offered by the institution to the society. This leads to inadequate training and therefore lower level skills in certain uncommon yet important surgical procedures. Internal iliac artery ligation is one such procedure, the need of which may strike as an emergency. This can become a crisis situation if experts to handle the situation cannot be made available. Therefore, better understanding of retroperitoneal structures and its topography should be an integral part of obstetrics and gynecological training; this creates confident and safe surgeons. Revising the anatomy, related to the subject of post-graduation, on cadavers for postgraduate students should be incorporated into the curriculum. For practicing gynecologists and obstetricians, it can be done by organizing cadaveric dissection workshop CMEs. ${ }^{5,6}$ Thus knowledge of designing and organizing such workshops is essential as these dissection sessions differ from traditional undergraduate anatomy dissection sessions. ${ }^{7,8,9}$ In our experience these workshops successfully upgraded the skills of delegates in understanding pelvic anatomy and utilizing this knowledge in the interest of patients. Such CMEs should be organized regularly and should be integrated into post-graduate curriculum.

\section{ACKNOWLEDGMENTS}

Authors like to thank Dr. Feroz Pathan, Associate Professor, Anatomy, MIMSR Medical College, Latur; Dr. Richa Singh, D Y Medical College, Professor Gynecology, New Mumbai; Dr. Sriram Gopal, D Y Medical College, Professor Gynecology, New Mumbai; Dr. Uddhav Mane, Associate Professor, Anatomy, SCGMC, Nanded; Dr. Sriniwas Gadappa, Professor Gynecology, GMC Aurangabad for their help as faculty in these dissection workshops.

Funding: No funding sources Conflict of interest: None declared

Ethical approval: The study was approved by the Institutional Ethics Committee

\section{REFERENCES}

1. Joshi V, Otiv S, Majumder R, Nikam Y, Shrivastava M. Internal iliac artery ligation for arresting postpartum haemorrhage. BJOG 2007; 114(3):35661.

2. Papp, Z; Tóth-Pál, E; Papp, C; Sziller, I; Gávai, M; Silhavy, M; Hupiczi, P. Hypogastric artery ligation for intractable pelvic hemorrhage. Obstet Gynecol Survey. 2006;61(4):224-6.

3. Wagaarachchi P.T, Fernando L. Fertility following ligation of internal iliac arteries for life-threatening obstetric haemorrhage: Case report. Human Reproduct 2000;15(6):1311-3.

4. Burchell RC. Physiology of internal iliac artery ligation. BJOG. 1968;75(6):642-51.

5. Ali A, Khan ZN, Konczalik W, Coughlin P, El Sayed S. The perception of anatomy teaching among UK medical students. Bul $\mathrm{R}$ Coll Surg Engl. 2015;97(9):397-400.

6. Charles M. Maliska, John W. Carter, John Blebea, Jeanne E. Gillert, Carmen Ruiz. Focused cadaveric dissection in surgical resident education. J Am Coll Surg. 2015;221(4):S52-3.

7. J Gilbody, AW Prasthofer, K Ho, ML Costa. The use and effectiveness of cadaveric workshops in higher surgical training: a systematic review. Ann R Coll Surg Engl 2011;93(5):347-52.

8. CL Gelder, S Paterson-Brown. The role of anatomy in surgical training and the use of cadaveric training courses. Bullet Royal Coll Surg England 2015;97(3):123-6.

9. Memon I. Cadaver Dissection Is Obsolete in Medical Training! A Misinterpreted Notion. Med Princ Pract 2018;27(2):201-10.

10. Reddy R, Iyer S, Pillay M,1 Thankappan K,2 Ramu J. Soft embalming of cadavers for training purposes: Optimising for long-term use in tropical weather. Indian J Plast Surg. 2017; 50(1):29-34.

Cite this article as: Mahale AR, Gosavi AG, Ugale MS, Diwan CV, Sukre SB. Learning internal iliac artery ligation and pelvic ureter course through cadaveric dissections. Int J Reprod Contracept Obstet Gynecol 2018;7:4516-20. 